\title{
Changing Patterns of Malaria in Grande Comore after a Drastic Decline: Importance of Fine-Scale Spatial Analysis to Inform Future Control Actions
}

\author{
Artadji Attoumane ${ }^{1}\left(\mathbb{D}\right.$, Rahamatou Silai $^{2}$, Affane Bacar ${ }^{2}$, Eric Cardinale ${ }^{3}$ (D), \\ Gwenaëlle Pennober ${ }^{1}$ and Vincent Herbreteau ${ }^{1, *(D)}$ \\ 1 ESPACE-DEV, IRD, Univ Réunion, Univ Montpellier, Univ Antilles, Univ Guyane, 97410 Saint-Pierre, \\ La Réunion, France; artadjiattoumane@gmail.com (A.A.); gwenaelle.pennober@univ-reunion.fr (G.P.) \\ 2 Programme National de Lutte Contre le Paludisme, Ministry of Public Health, BP521 Moroni, Comoros; \\ rsilai.pnlp@laposte.net (R.S.); anfanebacar@yahoo.fr (A.B.) \\ 3 CIRAD, UMR ASTRE, 97490 Sainte Clotilde, La Réunion, France; eric.cardinale@cirad.fr \\ * Correspondence: vincent.herbreteau@ird.fr
}

Received: 15 October 2020; Accepted: 8 December 2020; Published: 13 December 2020

\begin{abstract}
Malaria has long been endemic in the Union of Comoros reaching an incidence of 15,045 cases for 100,000 inhabitants in 2010 (103,670 cases). Since then, strengthened control actions based on the distribution of Long-Lasting Insecticidal mosquito Nets and mass treatment have reduced malaria to a low level. However, it persists more specifically in Grande Comore, where $82 \%$ of cases were diagnosed between 2010 and 2016. This situation remains a challenge for health authorities seeking to eliminate malaria, by targeting transmission sites more precisely. In this context, this study aimed at mapping malaria at the finest scale, in order to describe its spatial distribution and identify possible environmental indicators. The National Malaria Control Program provided the 2016 data, the only year that could be mapped at the level of localities. This mapping revealed spatial autocorrelation between localities, especially in the east of the island with a major cluster around Itsinkoudi (using the Kulldorff's spatial scan test). Secondary clusters showed that malaria remains present throughout the island in both rural and urban areas. We also analyzed satellite images (SPOT 5) with remote sensing techniques (Object-Based Image Analysis) to look for environmental indicators. Landscape analysis shows that malaria incidence is correlated across the island with low altitudes, and a larger proportion of grasslands or a fewer proportion of forested areas nearby (at less than $1 \mathrm{~km}$ around villages). More locally in the east, malaria is linked to larger shrub areas. These relationships could be associated with the fact that lower altitude localities are more interconnected, such facilitating malaria transmission. In 2016, malaria persists in Grande Comore, showing new patterns with more cases in the eastern part of the island and the possibility of high incidences during the dry season. Precise mapping of epidemiological data and landscape analysis allow the identification of clusters and active transmission foci. They are important tools for health surveillance in order to optimize control actions on key transmission locations.
\end{abstract}

Keywords: malaria; spatial analysis; remote sensing; landscape metrics; GIS; satellite; cluster; geostatistics; Grande Comore

\section{Introduction}

Malaria is a parasitic disease that remains a major cause of morbidity and mortality worldwide. In 2016, it affected 216 million people in 91 countries, mainly in sub-Saharan Africa, according to the latest WHO World Malaria Report [1]. In the Comoros archipelago, located in the southeast of the African continent, between Mozambique and Madagascar, malaria is an endemic disease. The Union 
of the Comoros currently groups together the islands of Grande Comore (Ngazidja), Mohéli (Mwali) and Anjouan (Ndzuwani) and benefits from favorable climatic and environmental conditions for malaria transmission. The first malaria deadly epidemic was reported in 1923 [2], but malaria has long been a major health problem before significant control actions were taken to limit its impact [3]. The highest number of cases was reported in 2010 with a total of 103,670 cases (incidence of 15,045 for 100,000 inhabitants). This situation triggered the will to strengthen the fight to achieve its elimination during the last fifteen years. Malaria has consequently largely decreased, particularly on the islands of Mohéli and Anjouan, classified in the pre-elimination phase, and on the island of Grande Comore, classified in the control phase [4]. The achievement of these results is strongly associated with mass treatment by Artemisinin Combination Therapy (ACT) performed on Moheli from 2007 to 2010 and on the other islands from 2012 to 2013 together with the distribution of Long-Lasting Insecticidal mosquito Nets (LLIN) [5-7].

The occurrence of malaria has always presented significant spatial disparities, both between the islands and within each island of the Comoros [8]. Higher malaria endemicity has been observed in Grande Comore since the 1990s [8]. Between 2010 and 2016, more than $82 \%$ of the malaria cases notified on the three islands were reported in Grande Comore. This reflects the persistence of Plasmodium parasites on this large island, despite control measures. This situation has also led to a greater research effort in Grande Comore than on the other islands, in order to characterize malaria epidemiology, vectors and parasites. Different epidemiological profiles have been described in Grande Comore according to the island's slopes and climate: malaria is hyperendemic throughout the year on the south-west slopes, hyperendemic in the rainy season and mesoendemic in the dry season on the north-west slopes and hyperendemic in the rainy season and hypoendemic in the dry season from the north to the south of the east slope [9]. Lower malaria endemicity has always been observed in villages at higher altitudes [8]. Using nested Polymerase Chain Reaction (PCR), a recent study identified the Plasmodium species responsible of malaria transmission in Grande Comore: mainly Plasmodium falciparum $(98.11 \%)$ and in rare cases Plasmodium vivax (1.25\%) and Plasmodium malariae (0.62\%) [10]. This study also indicates spatial variation in the parasite endemicity rate with $P$. falciparum hyperendemic in the east (Mbeni region), mesoendemic in the north-east (Mitsamiouli region) and hypoendemic in the west (in the capital city of Moroni). The plasmodial parasites are mainly transmitted in Comoros by Anopheles gambiae and Anopheles funestus [2] but Anopheles funestus is absent in Grande Comore [8].

In an insular context, the spatial variation in the level of malaria endemicity has been described as being associated with the variability in the physical environment, climate and human populations, independently of control actions [8]. In Grande Comore, access to water is a major problem for rural households due to the absence of streams and rivers [11,12]. People collect rainwater in shared reservoirs that can be found in all villages or private reservoirs in some houses. These reservoirs are generally not well covered and often contribute to the development of mosquito larvae and thus to the maintenance of malaria endemicity [3,8]. Anopheles gambiae has then been described as an anthropogenic species in Grande Comore [2]. Rainfall is also an important factor in the ecology of these mosquitoes and the spatial variations in rainfall on the island's slopes also affect mosquito densities.

After having dropped drastically to a low level, malaria has slightly increased since 2016 in Grande Comore. The persistence of malaria challenges health authorities, which are working to eradicate malaria with major control efforts already in place. They seek to understand more precisely the origin of the outbreaks, the places of persistence and to identify the factors contributing to its transmission. One way is to monitor more precisely how cases are distributed in space-i.e., to develop complete spatial decision support systems for disease surveillance [13]. This requires both knowledge of case location and near real-time notifications of case diagnosis from medical doctors to the health authorities in charge of surveillance [14]. On the one hand, it is generally possible to locate cases in their place of residence if the health facilities record this information and if reference maps exist at the village level. This requires electronic reporting of health data and harmonization and centralization of these data, which can come from different sources (public or private hospitals, humanitarian organizations, 
etc.) [15]. To this goal, geographical tools, more specifically geographical information systems (GIS) and geostatistical analyses, have made it possible to develop spatial disease surveillance [16-18]. However, such mapping assumes that people have got sick near their place of residence. On the other hand, real-time monitoring of case occurrence is generally more difficult because it requires rapid feedback and rapid diagnostic confirmations [19]. Some projects have set up a reporting system via mobile phones to quickly report the occurrence of cases [20,21] or control actions [22]. However, these methods are difficult to implement at the country level, where spatial analyses are generally based on data that are aggregated and adjusted annually by health authorities.

A second axis to improve the spatial understanding of diseases is to study the environmental, climatic or human factors related to their distribution [23]. These factors can simply be spatially correlated with the distribution of diseases without having a cause-and-effect relationship and can be used as indicators of occurrence [24]. These factors may also have a direct role on pathogens, vectors or facilitate transmission to humans. Such spatial analyses also use space technology tools-i.e., GIS, remote sensing and geostatistics [25]. Remote sensing has been increasingly used for health applications and especially malaria studies [26]. In a recent systematic review of spatio-temporal methods to map malaria risks, $46 \%$ of 107 articles used remotely-sensed climate or environmental information [27]. Nevertheless, most of these studies used low spatial resolution images or directly pre-calculated indices such as Normalized Difference Vegetation Index from MODIS images [28]. These vegetation indices have often been used as temporal indicators of seasonal fluctuations in disease $[29,30]$ or predictors to build malaria early-warning systems [21]. Remote sensing has also been applied to study malaria ecology using high spatial resolution images to identify relationships with land cover or land use [24,31]. In Madagascar, Rakotoarison et al. showed the potential of such remotely-sensed environmental analyses to map malaria risk and guide its control [32]. Based on a literature review, $\mathrm{Li}$ et al. built a landscape-based hazard index for malaria transmission in the Amazonian region [33]. They showed the potential of mapping land use/land cover to extract landscape indices and understand the distribution of malaria.

The objective of this study is to implement such spatial analysis methods to clarify the epidemiology of malaria in Grande Comore, in this context of persistence and slight increase. It aims to clarify the epidemiology of malaria at the finest possible scale in order to identify outbreaks, clusters and then environmental factors. However, in such a small territory, the methodological challenge is to carry out very detailed spatial analyses: on the one hand, it is necessary to know the places of residence of the cases and, on the other hand, to obtain very high-resolution environmental data.

\section{Materials and Methods}

\subsection{Study Area and Scales}

The Comorian health system is geographically organized with the islands constituting the health regions subdivided into health centers and then health districts. There are three health centers and seven health districts in Grande Comore. Generally, the epidemiological data are aggregated at the level of the health structures without precision on the origin of the patients. Some data can provide information on the location of patients at the village or city level, making it the finest scale. Malaria data are available at this scale only on Grande Comore, which was, therefore, chosen as the study area.

Grande Comore is the largest island (1148 sq. km) of the Union of Comoros (Figure 1). It has a hilly landscape dominated by Mount Karthala, an active volcano that rises at $2361 \mathrm{~m}$. The climate is tropical with two seasons: a hot and rainy season from November to April and a cool and dry season from May to October. The average temperature varies between 25 and $27^{\circ} \mathrm{C}$ during the warm season and between 22 and $24{ }^{\circ} \mathrm{C}$ during the cool season. The average rainfall ranges from 1500 to $2000 \mathrm{~mm}$ during the rainy season, and from 500 to $800 \mathrm{~mm}$ during the dry season. Because of the topography and the island context, rainfall varies spatially with more water on the slopes facing the monsoon winds. 
In total, 193 villages and 19 cities (or districts) were included in this study for a total of 212 locations. The capital city of Moroni is divided in 11 districts and there are eight other cities. Villages and cities are mainly located in coastal areas at less than $600 \mathrm{~m}$ altitude (Figure 1).

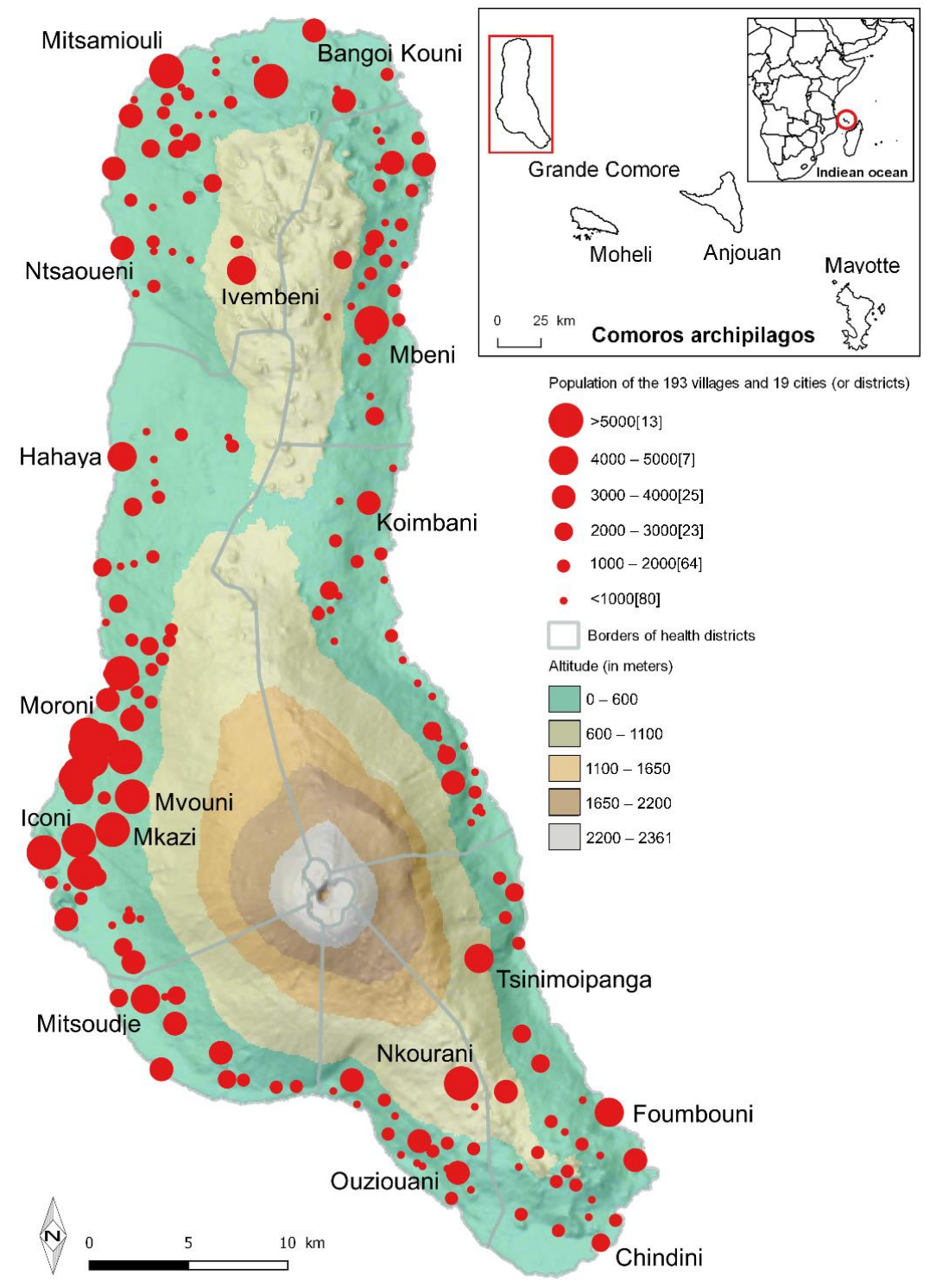

Figure 1. Location of Grande Comore, topography and population by locality in 2016.

\subsection{Epidemiological Data Collection}

The National Malaria Control Program, "Programme National de Lutte contre le Paludisme de 1'Union des Comores" (PNLP), provided the 2016 monthly epidemiological data on malaria at the village scale. The PNLP is the national authority in charge of collecting and analyzing malaria data and of controlling the disease in the Union of Comoros. All malaria cases diagnosed in the district health centers or in the village health posts are reported to the NMCP. In addition, the NMCP has implemented a more active monitoring at the village level. In each village, a community health worker conducts a Rapid Diagnostic Test (RDT) on people presenting fever. If this test is positive, a district health officer travels by motorcycle to the village to take a blood sample from the patient to confirm the case. If the diagnosis is confirmed, he reports the case to the NMCP by sending a message. Finally, patients who have visited a private health center are invited to come to the NMCP to obtain free medicines, which in turn allows completing the registration of cases. Malaria data have been optimized to be more comprehensive and the 2016 dataset is the first one at the village scale. 
The "Institut National de la Statistique et des Etudes Economiques et Démographiques" (INSEED) provided projections of demographic data calculated based on the last population census (realized in 2003). These data are projected up to 2025 and are national references pending the 2017 population census. The capital city is the most populated with a total of 55,540 inhabitants in its 11 districts. The eight other cities have populations ranging from 2848 to 8365 inhabitants. An amount of $37 \%$ of villages have less than 1000 inhabitants and only $6 \%$ of villages exceed 5000 inhabitants (Figure 1).

\subsection{Meteorological Data}

Monthly rainfall data from 2010 to 2016 were provided by the National Agency for Civil Aviation and Meteorology (Agence Nationale de l'Aviation Civile et de la Météorologie) of the Union of Comoros (ANACM). These data are collected at two stations at the airport (Hahaya) and Moroni.

\subsection{Land Cover Mapping Using Remote Sensing}

We applied satellite images remote sensing techniques to describe the environment around villages by realizing a land cover/land use map of Grande Comore. SEAS-OI Station at Réunion Island (http://www.seas-oi.org) provided two Spot 5 images (C CNES-2013, Distribution Astrium services/Spot images S.A., France, all rights reserved) acquired on 30 May 2013 (with few clouds). One image has a $2.5 \mathrm{~m}$ spatial resolution in panchromatic mode and the other one a $10 \mathrm{~m}$ spatial resolution in multispectral mode. We used ENVI software (v5.1) to correct geometrically the two images from topographic effects based on the SRTM (Shuttle Radar Topography Mission) digital elevation model integrated into ENVI as a reference. We applied the pansharpening algorithm (Gram-Schmidt Spectral Sharpening (GSSS)) to merge the two images and assign the resolution of the panchromatic image to the multispectral one. We reduced the radiometric values of clouds and shadows to zero to mask them and avoid confusion.

We performed an object-oriented classification of the images, which has the advantage of grouping pixels into objects with relatively homogeneous characteristics (regarding spectral values, texture and geometry) [34]. This method is particularly adapted to such high spatial resolution images [35] to obtain homogeneous areas for each class [36]. We used eCognition software (eCognition Developer 9.0.3, ( 2020 Trimble Germany $\mathrm{GmbH}$ ) to realize a supervised hierarchical classification. With this approach, we defined seven land cover/land use classes by referring to the Land Cover Classification System (LCCS) defined by the Food and Agriculture Organization (FAO). These classes are: built-up areas, bare lands, grasslands, shrubs, forests, mangroves and water areas.

For the validation of the land use map, we collected about 340 GPS locations representing each class during field surveys (about fifty observations per class). We used these observations to develop a confusion matrix between field recognition and spatial image classification. This matrix allows the calculation of an overall accuracy of the land cover/land use map and of the Cohen's Kappa index, which indicates the difference between the observed accuracy and what could be expected by chance. A map is considered as accurate when this index is over $75 \%$ [37].

\subsection{Landscape Metric Computation}

We used the land cover/land use map to calculate landscape indices around villages. Other studies have estimated the maximum distance of malaria transmission around the breeding sites of malaria vectors, the Anopheles mosquitoes, at two kilometers [31,38-40]. Then, we chose different buffer sizes with radii of $1,1.5$ and $2 \mathrm{~km}$ from the center of each village to see at which distance the indices will be most significant. We first calculated the proportion of each land cover/land use class within each buffer. We also measured other landscape metrics within these buffers with FRAGSTAT 4.2.1 software [41]: the patch density (PD-i.e., the proportion of patches per 100 hectares calculated from the number of patches within each buffer in relation to the buffer area), the edge density (ED-i.e., the sum of the edge length of each patch, multiplied by 10,000 to convert to hectares), the splitting index (SPLIT-i.e., the total landscape area $\left(\mathrm{m}^{2}\right)$ squared divided by the sum of patch area $\left(\mathrm{m}^{2}\right)$ squared, summed across all 
patches in the landscape), the Shannon's Diversity Index (SHDI-i.e., the minus sum, across all patch types, of the proportional abundance of each patch type multiplied by that proportion). We finally measured the average elevation in these buffers, using the SRTM digital elevation model.

\subsection{Spatial and Statistical Analyses}

We realized the maps and geoprocessing using QGIS software [42]. We used a geometric progression with common ratio 5, as a discretization method, to map malaria incidence at the village level and define class boundaries. In order to calculate the road distances between certain villages and see if their connections could help transmission, we used the free and participative OpenStreetMap database (https://www.openstreetmap.org). For these villages, we completed the layout of roads and paths (accessible by foot) and indicated the corresponding categories, using photointerpretation of satellite images in the OpenStreetMap iD interface. We then used QGIS to calculate the road distances between villages along these different routes.

We performed statistical analyses using R Software version 3.2.5 [43] with R-Studio environment [44]. We conducted a descriptive analysis of malaria cases monthly by village and by health district. We calculated malaria incidence for 100,000 inhabitants.

We calculated the Moran's I global index to determine the spatial autocorrelation in malaria incidence at the local scale (villages and cities), first for the whole island and second for each health district independently $[45,46]$. We hypothesized that the spatial distribution of malaria incidence is independent between localities. This test measures whether villages have malaria rates close to their neighbors, which would mean that spatial proximity has an impact on epidemiology and that villages are not spatially independent. We also calculated the Anselin Local Moran's I index for each locality, first within the whole island and second within each health district [47]. We used the spdep package developed under R (https://github.com/r-spatial/spdep/) to calculate these two indicators. Positive values of the indices with a $p$-value under 0.05 indicate a spatial autocorrelation of the average incidence between villages.

We used Kulldorff's spatial scan test [48] to identify spatial clusters of malaria incidence by village. This test scans village centroids through windows to determine which one has abnormally grouped more cases than expected using the maximum likelihood method [49]. For each significant cluster, the spatial scan test relates the observed number of cases to the suspected number of cases and also determines the relative risk (RR), defined as the risk of the given cluster compared to the risk in all other areas. The calculation of the probability of $p$-value is determined from the Monte Carlo 999 simulations method for cluster analysis [48].

We then conducted bivariate and multivariate analyses to find relations between landscape indices and malaria incidence. We first measured pair-wise correlations between landscape indices and malaria incidence at the village scale. We realized Principal Component Analyses (PCA) to understand the relations between environmental factors and identify groups of correlated variables. For each of these groups, we selected the most strongly associated variable (based on the likelihood ratio test) for further multivariable modelling. We also verified that the selected variables had pairwise correlation coefficients between -0.8 and 0.8 , to avoid multicollinearity. Then, we performed backward elimination regression modeling to see if malaria incidence can be modeled based on these environmental indices [50]. We selected the best models based on the Akaike Information Criterion (AIC). For the final models, we verified the absence of collinearity of the variables by calculating the Variance-Inflation Factors (VIF, which are acceptable if the square root of VIF is less than 2) [51].

\section{Results}

\subsection{Malaria Incidence}

In 2016, 1372 cases of malaria were reported in half of the villages and cities (116 villages-i.e., $54.7 \%$ ) of Grande Comore. This figure is very low compared to the very high numbers of cases recorded 
annually before 2014 (over 50,000 cases), and comparable to the years 2014 (2130 cases) and 2015 (1061 cases). This represents an average incidence of 334 cases per 100,000 inhabitants. Nevertheless, the incidence varies greatly between villages and districts (Figure 2). The first seven localities with the highest incidences are all in the eastern part of the island and of the first ten, only the seventh is in the western part (Hantsambou north of Moroni). Itsinkoudi, in the center east, recorded the highest incidence and also the highest number of cases (217 cases-i.e., 7231 cases per 100,000 population), followed by Ouroveni, in the south-east (108 cases-i.e., 6857 cases per 100,000 population). On the eastern side of Grande Comore, Oichili Dimani health district is particularly affected by malaria in 2016 as it includes many villages with high incidences. In total, 29\% (402/1372) of cases are located in this district, but being a rural district with a smaller population, its average incidence (925 cases per 100,000 inhabitants) is three times higher than the average incidence of all villages. Nevertheless, not all localities in the district are affected since $48 \%$ have not recorded any cases. Just over a third of malaria cases come from localities of the Centre health district (491-i.e., 36\% of cases). Since this district is the most populated with the capital city of Moroni, the average incidence per locality is lower with 235 cases per 100,000 inhabitants. In the Centre health district, the highest incidences are observed close to Moroni, in Hantsambou and some Moroni districts. Three health districts recorded particularly low incidences in their villages: Mitsamiouli Mboude district (71 cases per 100,000 inhabitants) in the north, Hambou (80) and Mbadjini Ouest (69) districts in the south-west.

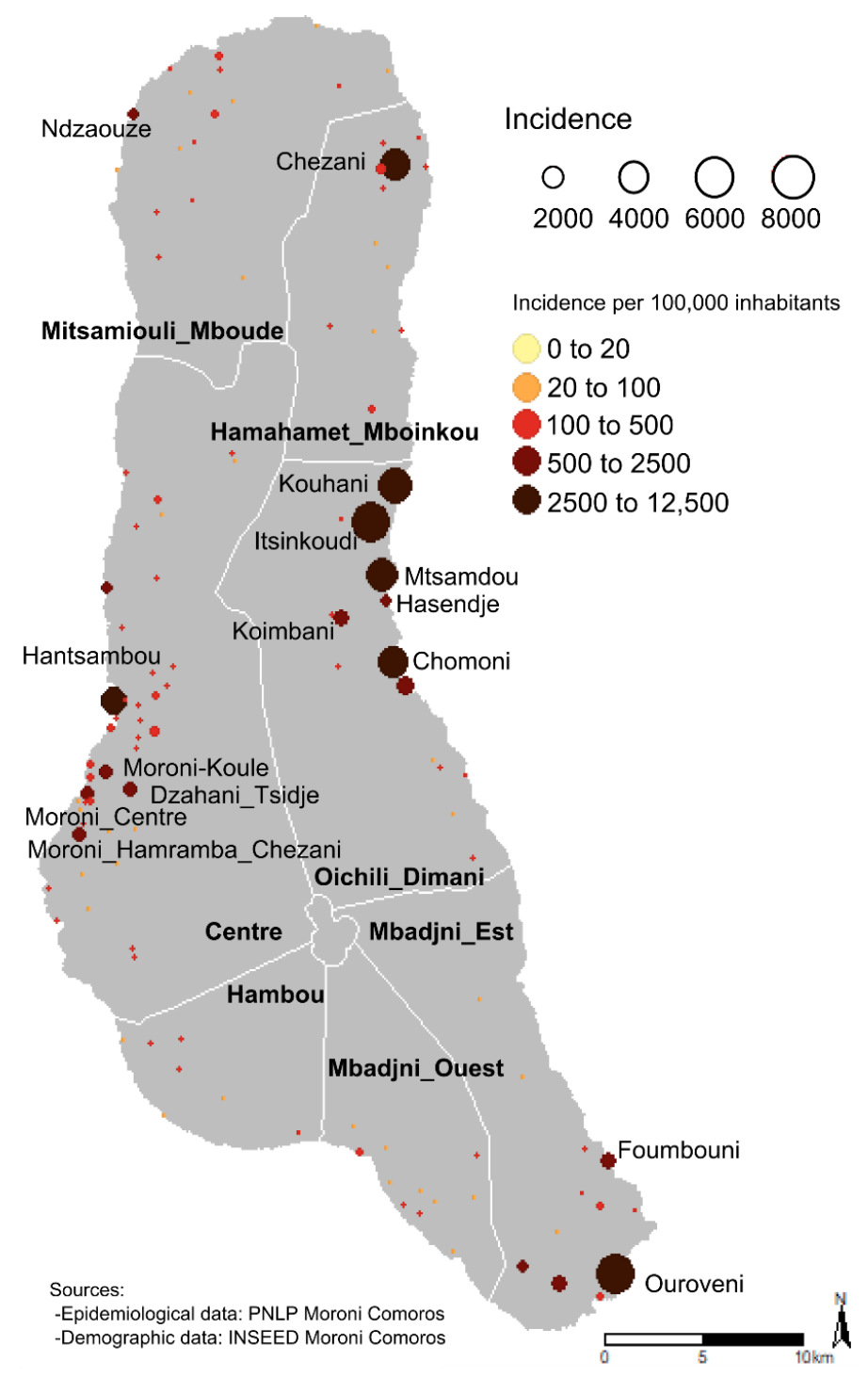

Figure 2. Malaria Incidence by locality in Grande Comore in 2016. 
Malaria occurs more in rural areas than in urban areas with an average prevalence of 356 cases per 100,000 inhabitants (1002 cases) per village compared to 295 cases per 100,000 inhabitants (370 cases) per city. Half of the villages (51\%-i.e., 95/193) and most of the cities (95\%-i.e., 18/19) recorded malaria cases in 2016.

Surprisingly in 2016, there were more malaria cases during the dry season (912 cases) than during the rainy season (459 cases) (Figure 3). The average incidence per village was 33 cases per 100,000 inhabitants in the dry season and 17 cases per 100,000 inhabitants in the rainy season. The variance test shows seasonal variation in malaria incidence across villages $(\mathrm{F}=9.56, p<0.01)$. At the district level, this seasonal variation in incidence by village is statistically significant only in the Centre health district $(\mathrm{F}=16.23, p<0.0001)$, with 33 cases per 100,000 inhabitants in the dry season and 6 cases per 100,000 inhabitants in the rainy season.

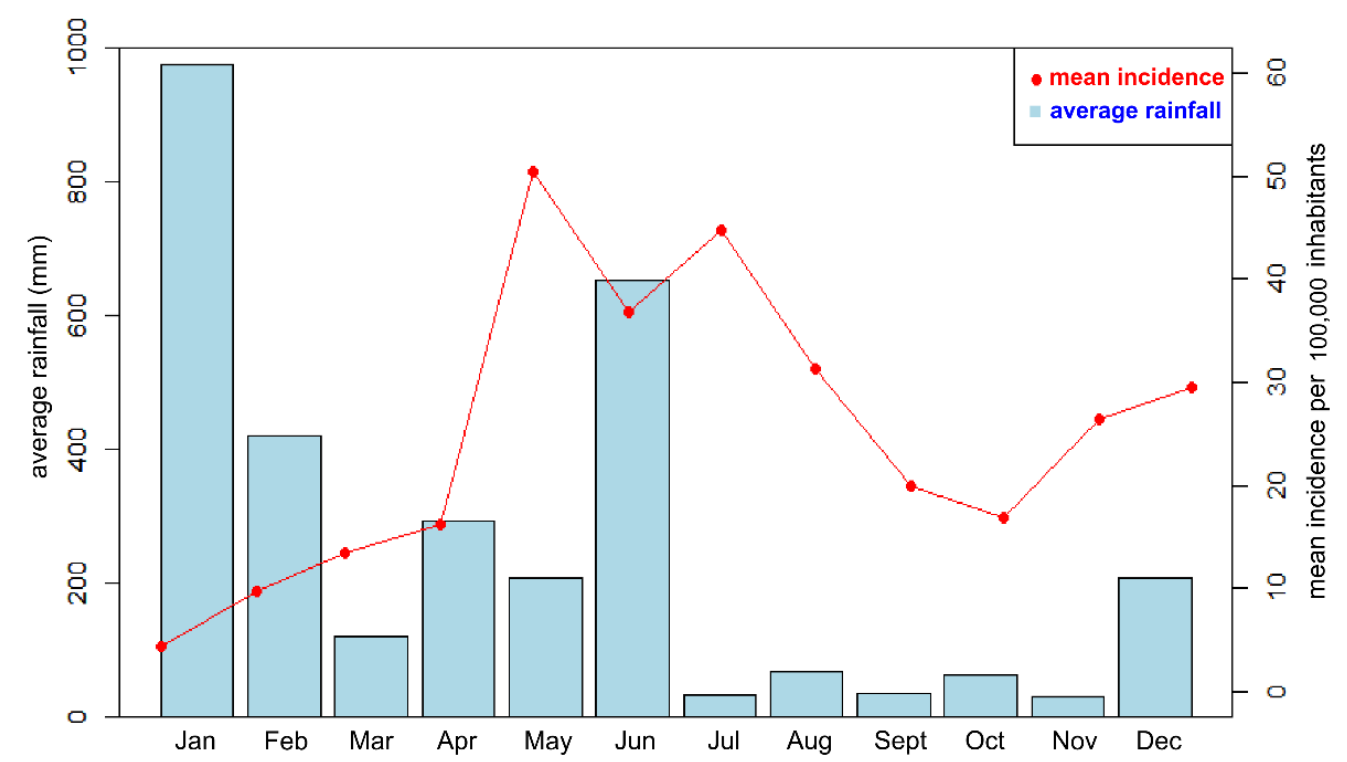

Figure 3. Monthly malaria incidence in Grande Comore and average rainfall in Moroni in 2016.

\subsection{Spatial Cluster Analysis}

The Moran's I coefficient showed the existence of a strong spatial autocorrelation of the incidence of malaria in a global way between the localities on the island of Grande Comore $(\mathrm{I}=5.49, p<0.001)$. Within health districts, spatial autocorrelation is only observed in the Oichili Dimani district $(\mathrm{I}=4.02, p$ $<0.001)$. The Anselin Local Moran's I index is statistically significant in five villages of Oichili Dimani district: Itsinkoudi $\left(\mathrm{I}_{\mathrm{i}}=13.46, p<0.001\right)$, Kouhani $\left(\mathrm{I}_{\mathrm{i}}=11.41, p<0.001\right)$, Mtsamdou $\left(\mathrm{I}_{\mathrm{i}}=6.40, p<\right.$ 0.001), Chomoni $\left(\mathrm{I}_{\mathrm{i}}=1.25, p<0.01\right)$ and Chamro $\left(\mathrm{I}_{\mathrm{i}}=1.44, p<0.01\right)$; and one of Mbadjini Est district: Simamboini $\left(\mathrm{I}_{\mathrm{i}}=0.78, p<0.01\right)$. This shows the existence of spatial influence and similarities in the average incidence between these villages and their very close neighbors.

Kulldorff's scanning method showed congruent results, with six clusters of malaria cases over the localities of Grande Comore. The most-likely cluster is in the east, in Oichili Dimani district, with five villages within a radius of $2.65 \mathrm{~km}$ (Figure 4 ). The observed number of malaria cases in the primary cluster is 13 times greater than expected with a relative risk (RR) of $17.48(p<0.001)$ (Table 1$)$. The RR of the five secondary clusters was also significant, ranging from 3.65 to 22,20 (with all $p<0.001$ ). The first three secondary clusters have no radius, meaning that these clusters are contained within the villages of Chezani in the northwest, Ouroveni in the southeast and Hantsambou in the west, respectively. They recorded more than 10 times the expected number of malaria cases. The fourth secondary cluster group two districts of Moroni (Dzahani Tsidje and Moroni Koule), within a radius of $1.46 \mathrm{~km}$ and twice the expected number of malaria cases $(R R=2.96, p<0.001)$. The southeastern localities of Koimbani ya Mbadjini and Fombouni form the fifth secondary cluster with a $1.47 \mathrm{~km}$ radius and an observed number of malaria cases three times higher than expected $(\mathrm{RR}=3.65, p<0.001)$. 


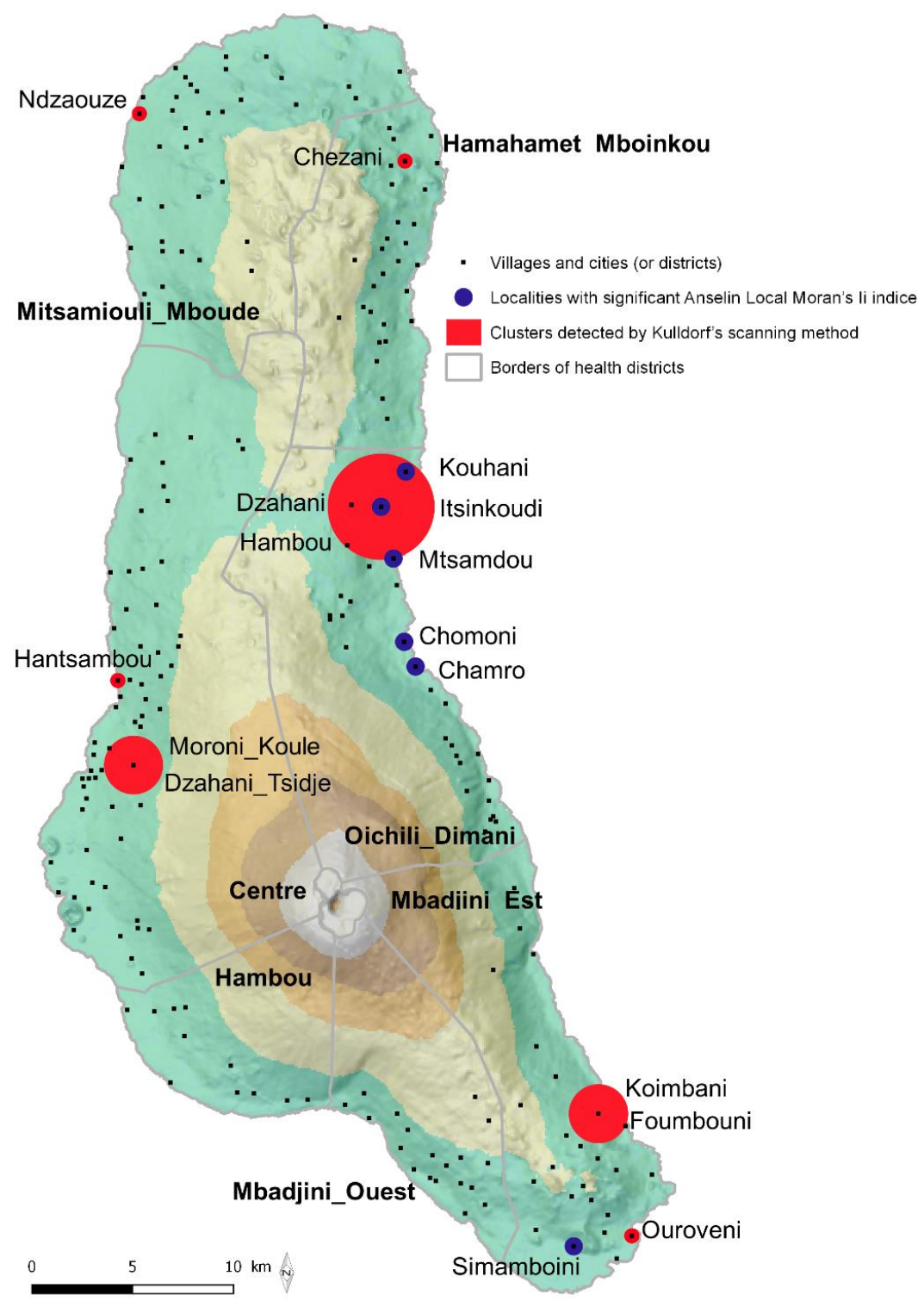

Figure 4. Location of malaria clusters and localities with significant Anselin Local Moran's I index in Grande Comore in 2016.

Table 1. Clusters determined by Kulldorff's scanning method.

\begin{tabular}{cccccccccc}
\hline Rank & Localities & Radius & Observed Cases & Expected Cases & ODE $^{1}$ & RR $^{2}$ & LLR $^{3}$ & $p$-Value \\
\hline & $\begin{array}{c}\text { Itsinkoudi } \\
\text { Dzahani ya Oichili } \\
\text { Kouhani } \\
1\end{array}$ & 2.65 & 325 & 23.94 & 13.58 & 17.48 & 583.11 & 0.00001 \\
& $\begin{array}{c}\text { Hambou ya Oichili } \\
\text { Mtsamdou }\end{array}$ & & & & & & & & \\
\hline 2 & Chezani & 0.00 & 140 & 10.67 & 13.12 & 14.49 & 237.38 & 0.00001 \\
\hline 3 & Ouroveni & 0.00 & 108 & 5.26 & 20.53 & 22.20 & 227.58 & 0.00001 \\
\hline 4 & Hantsambou & 0.00 & 64 & 6.14 & 10.43 & 10.89 & 93.44 & 0.00001 \\
\hline 5 & $\begin{array}{c}\text { Dzahani Tsidje } \\
\text { Moroni Koule }\end{array}$ & 1.46 & 199 & 74.35 & 2.68 & 2.96 & 77.45 & 0.00001 \\
\hline 6 & $\begin{array}{c}\text { Koimbani ya Mbadjini } \\
\text { Foumbouni }\end{array}$ & 1.47 & 63 & 17.86 & 3.53 & 3.65 & 35.03 & 0.00001 \\
\hline
\end{tabular}

${ }^{1} \mathrm{ODE}=$ Observed Divided by Expected, ${ }^{2} \mathrm{RR}=$ relative risk,${ }^{3} \mathrm{LLR}=\log$-likelihood ratio. 


\subsection{Land Cover}

Spot 5 images allowed us to realize a detailed land cover/land use classification for Grande Comore (Figure 5). The overall accuracy is reasonable ( $80.6 \%$ of correct observations), which results in a Kappa of $77.3 \%$ (95\% confidence interval from 0.73 to 0.82 ). The lowest accuracy was obtained from forested areas (65.8\%) with some confusion with shrub areas (67.7\%) (Table S1). Forested areas are the dominant land cover on the island $(45 \%)$ and concern mainly the districts located on the south-west and south-east slopes of the Karthala mount: Hambou (81\%), Mbadjini Ouest (79\%), Centre (50\%) and Mbadjini Est (43\%). In the north of the island, grasslands are the most common, especially in the districts located on the northeastern coast: Oichili Dimani (51\%) and Hamahamet Mboinkou (38\%). Shrub vegetation is an intermediate class between forest and herbaceous vegetation. It covers less than $25 \%$. It is more observed in districts mainly covered by herbaceous vegetation and less in forested districts. Built-up areas and bare lands represent less than 10\% of Grande Comore. The Central district is the most urbanized (3\%) with the capital Moroni.

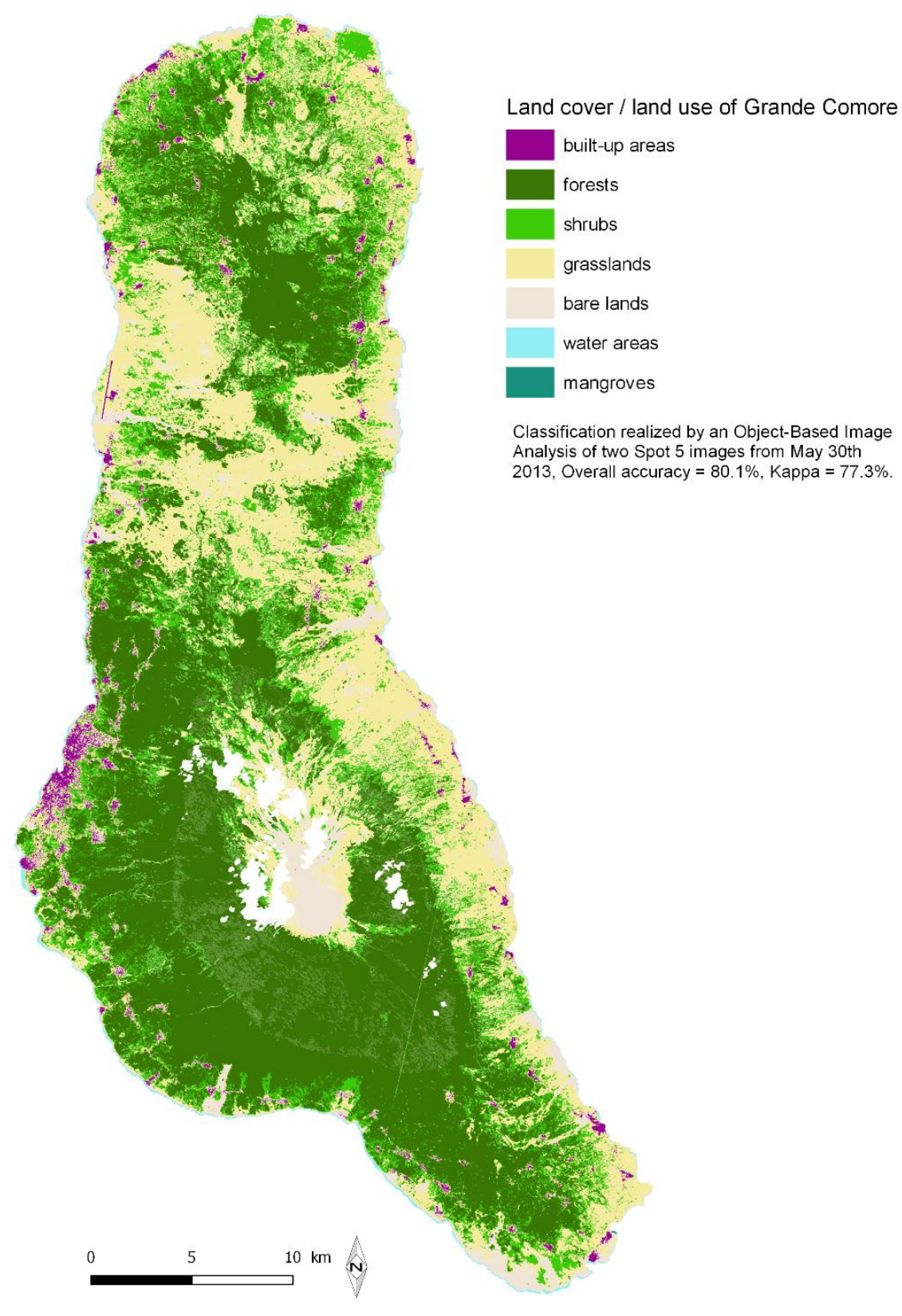

Figure 5. Land cover/land use map of Grande Comore. 
Landscape indices allow a distinction between homogeneous (example of Batou in Figure 6a and fragmented landscapes (example of Koua ya Mitsamiouli in Figure 6b. The patch density (PD) and Shannon's Diversity (SHDI) indices calculated between one and two kilometers in a fragmented landscape are double that of a homogeneous one (Figure 6c,e). This difference is almost multiplied by four for the edge density (ED) (Figure 6d) and by 13 for splitting index (SPLIT) (Figure 6f).

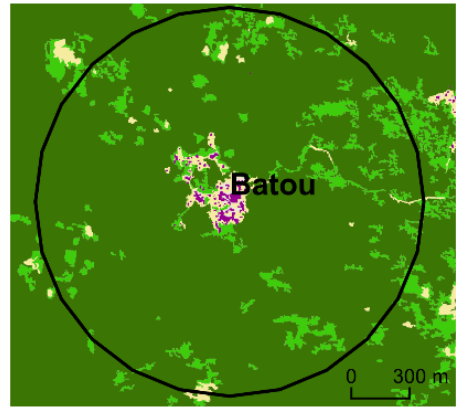

a) Zoom on a homogeneous environment at $1 \mathrm{~km}$

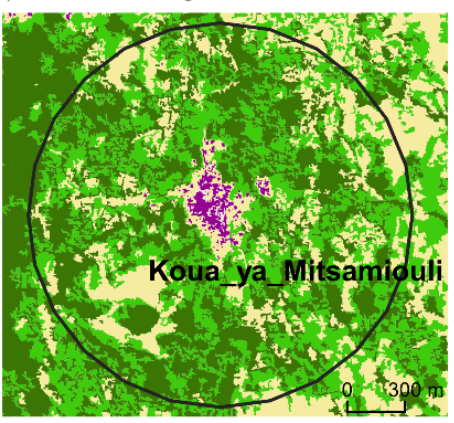

b) Zoom on a fragmented environment at $1 \mathrm{~km}$

Land cover/ land uses

built-up areas $\square$ forests

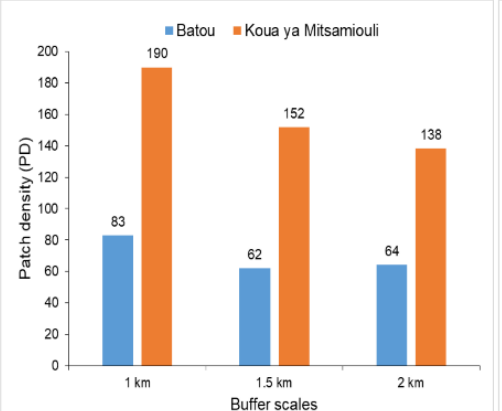

c) Evolution of the PD per village and buffer "Batou $=$ Koua ya Mitsamiouli

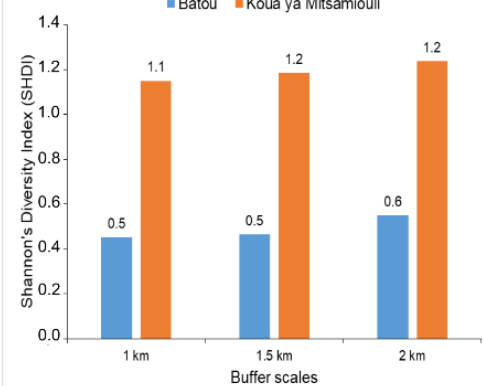

e) Evolution of the SHDI per village and buffer

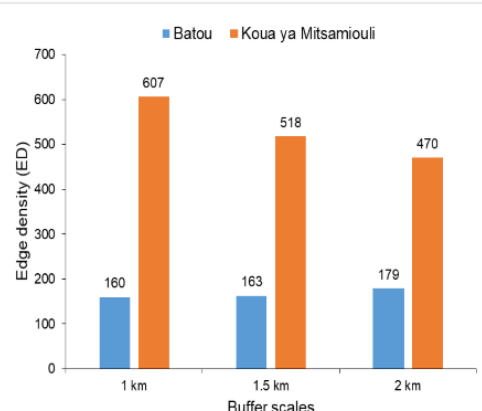

d) Evolution of the ED per village and buffer " Batou "Koua ya Mitsamiouli

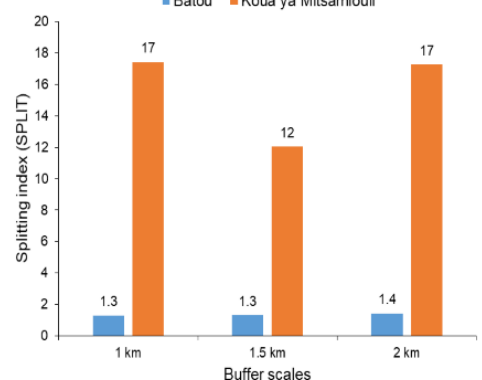

f) Evolution of the SPLIT per village and buffer

Figure 6. Comparison of landscape indices between a homogeneous and a fragmented environment.

\subsection{Statistical Analyses}

Malaria incidence at the village scale is positively correlated with the proportion of grasslands in the buffer zones (this applies to all three buffer sizes) and negatively correlated with the proportion of forests and the average elevation (also for the three buffer sizes) (Table 2). These correlations between incidence and grasslands or forests are strongest for small $1 \mathrm{~km}$ buffers (grasslands: $\mathrm{r}=0.17, p<0.01$, forests: $\mathrm{r}=-0.20, p<0.05)$. They are equal regardless of the size of the buffer for average elevation $(\mathrm{r}=-0.17, p<0.01)$. None of the other landscape indices are correlated to the incidence in Grande Comore. The PCA analysis also confirms the strong relationship in Grande Comore between incidence, forests, grasslands and mean elevation (Figure 7). The other landscape indices form another orthogonal group with PD, ED, SPLIT, SHDI and the proportion of built-up areas. Correlation between these indices increase with buffer size in Grande Comore.

By looking more locally within each district, we can highlight some other correlations. In Oichili Dimani district, malaria incidence is positively correlated to the proportion of shrubs within the $1 \mathrm{~km}$ and $2 \mathrm{~km}$ buffers (Table 2). It is also negatively correlated to average elevation. In Centre district, it is strongly positively correlated to the patch density and edge density indices within the $1 \mathrm{~km}$ and $1.5 \mathrm{~km}$ buffers. In Mbadjini Est district, it is positively correlated to the proportion of bare lands within the $1 \mathrm{~km}$ and $1.5 \mathrm{~km}$ buffers and to built-up areas within the 1.5 and $2 \mathrm{~km}$ buffers. In Mbadjini Ouest district, it is only positively correlated to the splitting index (SPLIT) within the 1 and $1.5 \mathrm{~km}$ buffers. In Hambou district, it is only negatively correlated to the Shannon's index (SHDI) within the 1.5 km buffers (Table 2). In the two other districts (Mitsamiouli_Mboude and Hamahamet_Mboinkou), no significant correlation was observed. 
Table 2. Results of linear regression analysis between environmental variables and malaria incidence (in Grande Comore and the 5 districts where significant correlations are observed).

\begin{tabular}{|c|c|c|c|c|c|c|c|c|c|c|}
\hline \multirow[b]{2}{*}{ Scales } & \multirow[b]{2}{*}{$\begin{array}{l}\text { Landscape } \\
\text { Metrics }\end{array}$} & \multicolumn{3}{|c|}{$1 \mathrm{~km}$ Buffer } & \multicolumn{3}{|c|}{$1.5 \mathrm{~km}$ Buffer } & \multicolumn{3}{|c|}{$2 \mathrm{~km}$ Buffer } \\
\hline & & $\mathbf{r}$ & $\mathbf{R}^{2}$ & $p$-Value & $\mathbf{r}$ & $\mathbf{R}^{2}$ & $p$-Value & $\mathrm{r}$ & $\mathbf{R}^{2}$ & $p$-Value \\
\hline \multirow{3}{*}{$\begin{array}{l}\text { Grande } \\
\text { Comore }\end{array}$} & Forests & -0.20 & 0.04 & 0.004 & -0.15 & 0.02 & 0.028 & -0.16 & 0.02 & 0.018 \\
\hline & Grasslands & 0.17 & 0.03 & 0.009 & 0.15 & 0.02 & 0.027 & 0.14 & 0.02 & 0.038 \\
\hline & Mean elevation & -0.17 & 0.03 & 0.009 & -0.17 & 0.03 & 0.009 & -0.17 & 0.03 & 0.009 \\
\hline \multirow{2}{*}{$\begin{array}{l}\text { Oichili Dimani } \\
\text { district }\end{array}$} & Shrubs & 0.37 & 0.13 & 0.047 & 0.36 & 0.13 & 0.053 & 0.37 & 0.14 & 0.045 \\
\hline & Mean elevation & -0.38 & 0.15 & 0.037 & -0.38 & 0.15 & 0.037 & -0.38 & 0.15 & 0.037 \\
\hline \multirow{2}{*}{ Centre district } & PD & 0.37 & 0.14 & 0.002 & 0.27 & 0.07 & 0.033 & 0.23 & 0.05 & 0.064 \\
\hline & ED & 0.30 & 0.09 & 0.016 & 0.19 & 0.03 & 0.124 & 0.14 & 0.02 & 0.249 \\
\hline \multirow{2}{*}{$\begin{array}{c}\text { Mbadjini Est } \\
\text { district }\end{array}$} & Bare lands & 0.48 & 0.23 & 0.012 & 0.48 & 0.23 & 0.011 & 0.35 & 0.12 & 0.072 \\
\hline & Built-up areas & 0.31 & 0.09 & 0.120 & 0.47 & 0.22 & 0.014 & 0.43 & 0.18 & 0.026 \\
\hline $\begin{array}{c}\text { Mbadjini } \\
\text { Ouest district }\end{array}$ & SPLIT & 0.49 & 0.24 & 0.031 & 0.57 & 0.33 & 0.009 & 0.39 & 0.15 & 0.095 \\
\hline $\begin{array}{c}\text { Hambou } \\
\text { district }\end{array}$ & SHDI & -0.55 & 0.30 & 0.079 & -0.60 & 0.36 & 0.047 & -0.48 & 0.23 & 0.127 \\
\hline
\end{tabular}

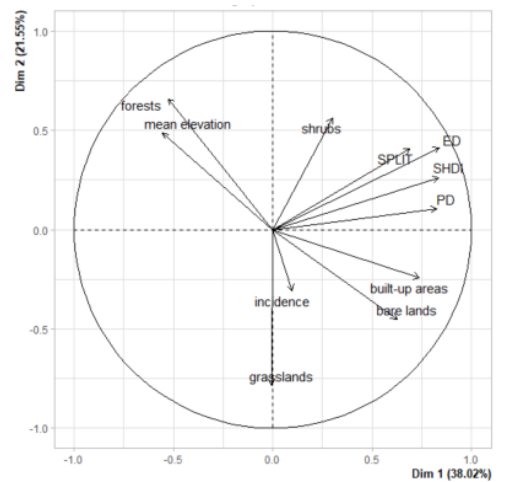

$1 \mathrm{~km}$

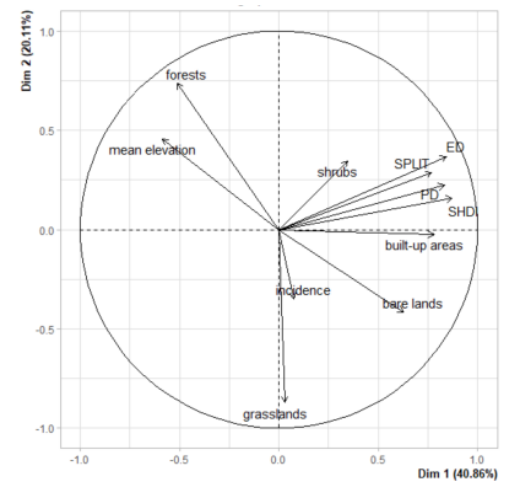

$1.5 \mathrm{~km}$

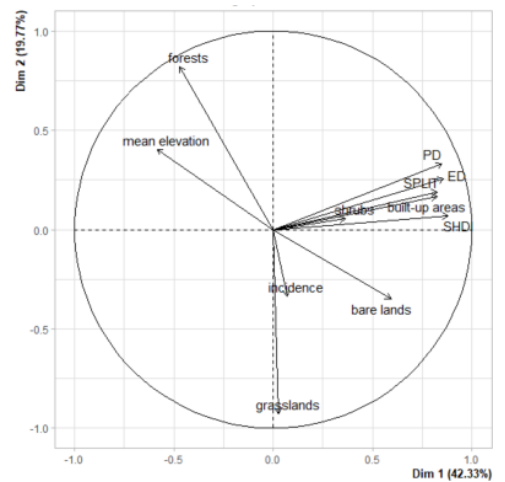

$2 \mathrm{~km}$

Figure 7. Correlation plot of the PCA analyses with the three buffer sizes in Grande Comore.

For multiple linear regressions, we removed two variables strongly correlated to others to avoid multicollinearity: grassland (highly correlated to forests $(\mathrm{r}=-0.82, p<0.001)$ and since grassland is less correlated to incidence than forest) and built-up areas (highly correlated to patch density $(\mathrm{r}=-0.85$, $p<0.001$ ), and since built-up areas are less correlated to incidence than patch density). In all the localities over the island, no multiple regression models could be compiled. The backward elimination regression only retains the proportion of forests in a simple model $(p<0.01)$ (Table 3$)$. If we consider only those localities that have had at least one case (116 localities), we obtained a model based on forest proportions and patch density. If we look at the villages more locally, we obtained different models. When considering the three eastern districts (Hamahamet Mboinkou, Oichili Dimani and Mabdjini Est, for a total of 83 localities), the backward elimination regression keeps the proportion of forests and shrubs to model incidence. Within these districts, if we focus only on localities having only one case (39), we found only the average elevation as correlated to incidence. Finally, when focusing on Oichili Dimani district (29 localities), the multiple linear regression allows to predict malaria incidence from the proportion of shrubs and the average elevation (Table 3).

For the other districts, we could not obtain any significant multiple linear regression. 
Table 3. Results of multiple linear regression at different scales (only significant regressions are shown).

\begin{tabular}{cccccc}
\hline $\begin{array}{c}\text { Scales of Model (Number of Villages) } \\
(p \text {-Value of the Model) }\end{array}$ & Variable & Estimate & Standard Error & $t$-Value & $p$-Value \\
\hline \multirow{2}{*}{ All villages $(212)(p<0.005)$} & (Intercept) & 543.706 & 107.001 & 5.081 & $<0.001$ \\
\cline { 2 - 6 } & Forests & -7.267 & 2.509 & -2.896 & $<0.005$ \\
\hline \multirow{3}{*}{ All villages with cases $(116)(p<0.01)$} & (Intercept) & 1344.344 & 318.950 & 4.215 & $<0.001$ \\
\cline { 2 - 6 } & Forests & -13.604 & 4.357 & -3.122 & $<0.005$ \\
\cline { 2 - 6 } & Patch density & -1.756 & 1.124 & -1.563 & 0.121 \\
\hline \multirow{2}{*}{ Eastern districts $(83)(p<0.005)$} & (Intercept) & 981.856 & 236.323 & 4.155 & $<0.001$ \\
\cline { 2 - 6 } & Forests & -9.174 & 3.023 & -3.035 & $<0.001$ \\
\hline \multirow{2}{*}{ Eastern districts with cases $(39)(p<0.05)$} & Shrubs & -15.341 & 7.248 & -2.117 & $<0.05$ \\
\cline { 2 - 6 } & Average elevation & -4.565 & 1.785 & -2.557 & $<0.05$ \\
\hline \multirow{2}{*}{ Oichili Dimani District $(29)(p<0.001)$} & (Intercept) & 1092.500 & 544.141 & 2.008 & 0.0552 \\
\cline { 2 - 5 } & Shrubs & 124.153 & 26.408 & 4.701 & $<0.001$ \\
\cline { 2 - 6 } & Average elevation & -10.248 & 2.144 & -4.779 & $<0.001$ \\
\hline
\end{tabular}

\section{Discussion}

Mapping a disease at the locality level allows us to identify areas of over- or under-incidence, to search for clusters, and to see if there are spatial correlations between localities or with environmental factors. Here, the methods used (autocorrelation tests vs. cluster detection) are relatively different and the map (Figure 4) aims to see if there is a concordance of the results. This study reveals first of all that the eastern region is particularly affected by malaria with several distinct clusters. The autocorrelation analyses also show a strong spatial autocorrelation overall on the island (through the calculation of Moran's I global index), which reflects similar epidemiological situation between close villages or districts. This is especially the case in the eastern Oichili Dimani district, where was detected the most-likely cluster with Kulldorff's scanning method. The highest Anselin Local Moran's I index was found in Itsinkoudi of Oichili Dimani district and followed by four other villages of the same district (Kouhani, Mtsamdou, Chomoni and Chamro). Looking at the monthly occurrence of cases, we can see the important role of the village of Itsinkoudi, which not only has the highest incidence but is also the first to report a large number of cases (Figure 8). The occurrence of cases in Kouhani starting in May and then in Mtsamdou in June could be directly linked to this village of Itsinkoudi. A similar pattern was observed in Chomoni with an increase in cases starting in May. One hypothesis could be that the geographical location of Itsinkoudi explains in 2016 the malaria transmission to other connected villages through population mobility. Itsinkoudi is the most populated city and is located at the intersection of the roads linking the other villages (at less than $3 \mathrm{~km}$ ). A further $1.5 \mathrm{~km}$ west of Itsinkoudi and, therefore, at a higher altitude (420 against $170 \mathrm{~m}$ for Itsinkoudi), is the village of Dzahani Ya Oichili, which recorded only one case of malaria in 2016. This village is geographically isolated, with a direct connection to Itsinkoudi only via a $2.1 \mathrm{~km}$ trail or, alternatively, by road, via the village of Hambou for a total distance of $5.5 \mathrm{~km}$. Thus, we can hypothesize that the village of Dzahani Ya Oichili has recorded few cases, as it is less connected to Itsinkoudi, despite a short distance "as the crow flies", but difficult trips for the villagers. Unfortunately, we do not have data from other years to verify the importance of connections between villages in malaria transmission.

In the Centre health district, Moroni Koule district and Dzahani Tsidje village form a significant cluster. The monthly observation of cases also confirms the synchronicity of the increase starting in May (Figure 9). Further north on the main road, the village of Hantsambou had an increase in cases over the same period, but this was not the case for villages located between. 


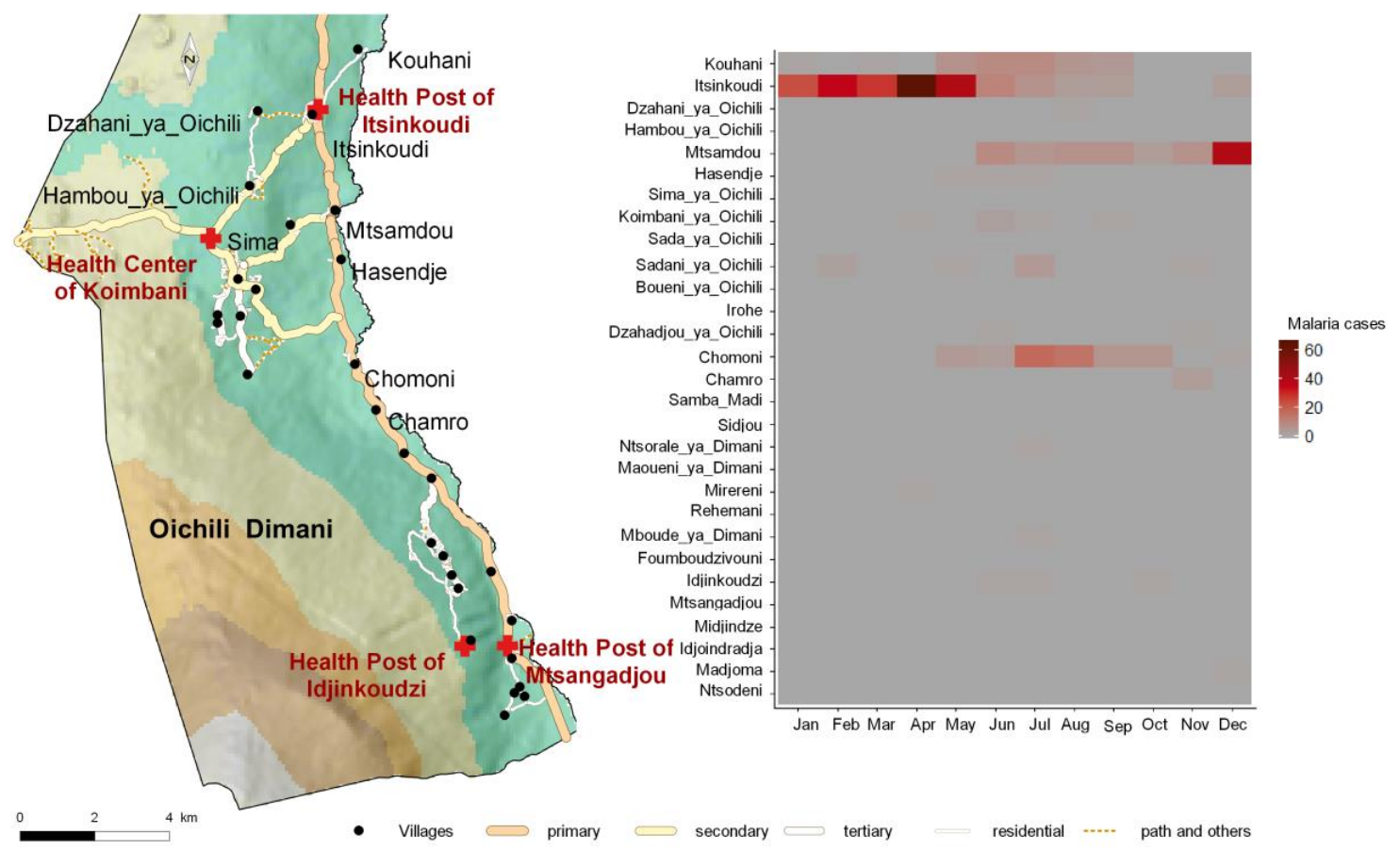

Figure 8. Monthly malaria cases by locality of the Oichili Dimani health district in 2016 and location map (localities are sorted from north to south).

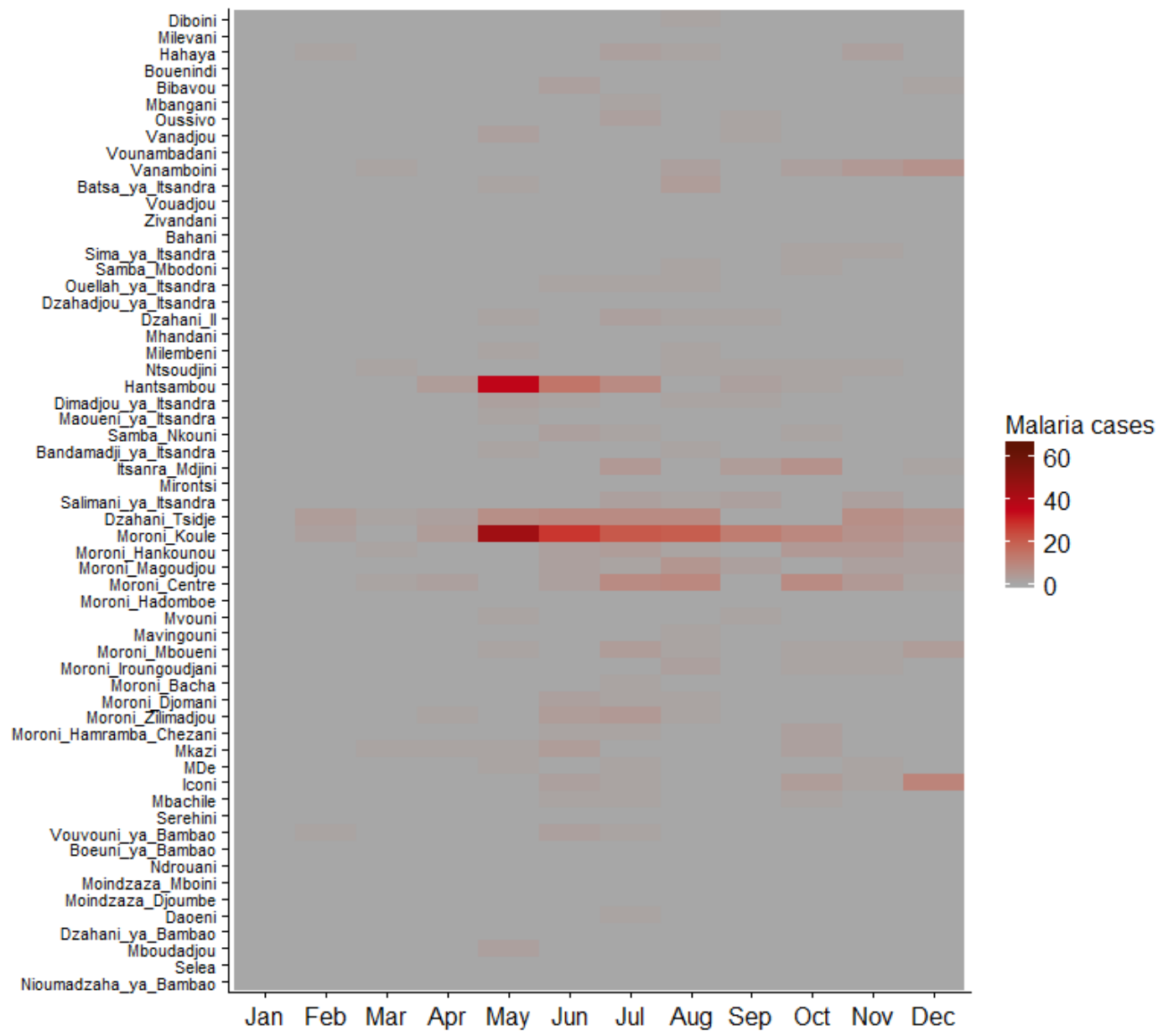

Figure 9. Monthly malaria cases by locality of the Centre health district in 2016 (localities are sorted from north to south). 
A surprising result is the higher number of cases recorded during the dry season in 2016 (Figure 4), which is contradictory with the patterns observed before 2014, where malaria is hyperendemic during the rainy season. The transmission of malaria in Grande Comore is usually amplified by rainfall [3] and, therefore, malaria is seasonal and can present geographical particularities according to the variations of the climate on the island [9]. The meteorological data to which we had access are very limited with only two stations in the west of the island, near Moroni. Rainfall data on other sides of the island would help to refine these observations. Nevertheless, the 2016 values in Moroni remain within the known seasonal averages in the Comoros, except for June with heavy rains (653 $\mathrm{mm}$ in 2016, representing 3.5 times the 2010-2016 average). The distinction of the seasons is made on a simple dichotomy according to the months. However, these data indicate that the study's wet season (November 2015 to April 2016) had rainfall similar to the 2010-2016 average (2160 $\mathrm{mm}$ compared to $2072 \mathrm{~mm}$ on average). During this wet season, the number of cases remained very low, as it has been since 2014, under the effect of control actions. Thus, the significant increase in incidence in May 2016 just follows the rainy season but is still surprising, while rainfall remained low in March, April and May. In June 2016, the unusual high rainfall may have contributed to maintain high prevalence from June to August. However, looking at the monthly data, we can see great temporal variation from one village to another, as in Itsinkoudi, which recorded more cases during the wet season and in Kouhani and Mtsamdou where it was the opposite. These substantial differences can also be explained in a context where malaria has reached a low level. A recent study in Madagascar has also noted that malaria control interventions could lead to a delay in the timing of malaria transmission [52]. Focusing on local data shows the importance of having spatially accurate epidemiological data and that aggregation at administrative scales can hide local disparities by using averaged data.

Autocorrelation analyses allow the detection and localization of clusters without, however, explaining their presence. The existence of these clusters suggests transmissions between the localities of each cluster and, therefore, that these localities are connected with mobile populations. These clusters can also reflect favorable and similar environmental conditions in the localities of the same cluster, due to their proximity. The results of the spatial analysis show trends in relation to environmental factors but they are not very conclusive in describing favorable environmental conditions. The distribution of malaria cases shows high incidences on both sides of the island in both urban and rural localities. Across the island, the environmental analysis highlights a correlation link with three environmental variables: malaria decreases with altitude and forested areas and increases with grasslands. These three variables are correlated with each other, forest cover being greater at higher elevations to the detriment of herbaceous areas. The variable grasslands had to be removed from the multivariate analyses for this reason. These analyses also identified through multiple regressions either forests or average altitudes as important predictive factors. However, these statistical relationships do not reflect a cause-and-effect relationship but rather characterize places that are conducive to transmission. The higher incidences of malaria at lower elevations can also be associated with the road network that contributes to its spread. Indeed, major roads around the island that connect the main villages are located at lower elevations. Access to villages at higher elevations is generally by secondary roads or even paths. They are therefore less used, which limits the spread of malaria to higher altitude areas. Nevertheless, links with the environment are likely to be found at a more local level. Oichili Dimani health district, which has the most-likely cluster and many high incidence villages, is also the district of Grande Comore with the smallest area of forest (22\%, unlike Mbadjini West district, which is covered with forests on over $79 \%$ of its surface). When focusing the analysis in Oichili Dimani, we found that shrub vegetation in the proximity of villages is a significant predictor of malaria incidence together with average elevation in a multiple linear regression. These results are consistent with another study in Ghana-methodologically close-which showed that the increase in the proportion of forests around villages was associated with a decrease in malaria [31]. We can also consider whether the negative effect of altitude on malaria is related to mosquito ecology. Several studies have shown a similar effect on malaria, as in Malawi or Tanzania [53,54]. In Grande Comore, more than $90 \%$ of the villages are located at an altitude of less than 
$600 \mathrm{~m}$ and the main vector species, Anopheles gambiae, is likely to live at these altitudes. Indeed, a recent study in Madagascar showed its presence at much higher altitudes [55]. In the Centre health district, malaria incidence is positively correlated with two landscape indices, characteristic of fragmentation (the patch and edge densities). This is consistent with a study at the border between French Guiana and Brazil, which showed similar association between the same fragmentation indices and the prevalence of Plasmodium falciparum [33]. We can finally note that significant models of multiple linear regressions between incidence and environmental variables were found in the eastern part of the island where there are the most-likely clusters and spatial autocorrelation.

Characterizing environment through the analysis of high-resolution satellite images, this study identified environmental factors and landscape indicators that promote malaria transmission at a very fine scale. The increasing availability of satellite data with very high spatial resolution, both optical and radar, as well as the development of analytical methods (including artificial intelligence and ensemble modelling) will also help in the integration of fine environmental information for future malaria studies [56].

The next steps in this study could be to work on connections between villages, to model population movements in order to anticipate the spread of malaria when an outbreak occurs in a village. This could be measured with network analyses to estimate interactions between villages. The use of mobile phone data has also shown the possibility of quantifying population movements and characterizing the directions of travel. In Madagascar, it has thus been possible to identify the sources and sinks for the importation of malaria from epidemic areas to low transmission areas [57]. In a small territory such as Grande Comore, field investigations should also be considered to characterize population movements, and, more specifically, to understand the social and cultural factors that drive these movements (and which will be unseen by mobile phone data). For instance, there are regularly large gatherings in villages for wedding ceremonies or funerals. These social factors are also essential determinants to be taken into account in order to better characterize the risks of malaria transmission [58].

\section{Conclusions}

By mapping malaria on a fine scale in 2016, this study allows to clarify its epidemiology in Grande Comore following the drastic reduction in the number of cases since 2014. Malaria is still very prevalent, with most localities affected. Grande Comore remains at the control phase, while the other islands are in the pre-elimination phase [4]. This study reveals a changing pattern of malaria: before 2015, the incidence was higher in the western part of the island [9] and, in 2016, higher incidences were observed in the eastern part. Furthermore, it specifies the localities and clusters with high incidences that should be targeted for control actions. It also shows trends between malaria and environmental factors, but above all it highlights local spatial heterogeneity with the possibility of villages with high incidences, while their neighbors may not be affected. Other studies have shown that mapping cases at an even finer scale, in their place of residence, can reveal disparities in exposure to the disease. For example, in Ghana, an increasing distance between children's households and the fringe of forests protects against malaria [59]. Proximity and human mobility seem to drive malaria epidemiology between these villages by facilitating transmission (via the transport of mosquitoes or the movement of infected people). This study thus shows the importance of precision mapping at a fine scale, which has never before been addressed in the Comoros for malaria. It is important that in the future data can be mapped and analyzed in this way in order to track malaria dynamics over time and space and to optimize control actions.

Supplementary Materials: The following is available online at http://www.mdpi.com/2072-4292/12/24/4082/s1, Table S1: Confusion matrix between field recognition and image classification.

Author Contributions: Conceptualization, A.A., R.S. and V.H.; Methodology, A.A., G.P., E.C. and V.H.; Data curation, A.A., R.S. and A.B.; Formal analysis, A.A. and V.H.; Writing-original draft, A.A. and V.H.; Writing-Review and Editing, All authors. All authors have read and agreed to the published version of the manuscript. 
Funding: This research was funded by IRD through the PhD scholarship ARTS Program attributed to Artadji Attoumane, and by "Fonds de Coopération Régionale" from Préfecture of La Réunion, for the GeoH2O project.

Acknowledgments: We sincerely thank the Ministry of Health of the Union of the Comoros and the National Malaria Control Program for supporting this work and for providing epidemiological data. We are grateful to the IRD for funding the thesis of Artadji Attoumane on malaria in the Comoros, through the ARTS program. We also thank INTERREG FEDER TROI 2015-2017 under the DP One health Indian Ocean (www.onehealth-oi.org) for connecting the different health actors in the Indian Ocean. We thank CNES and SEAS-OI Station for providing satellite images free of charge to this study, the National Institute for Statistics and Economic and Demographic Studies (INSEED) for providing demographic data, and the National Agency for Civil Aviation and Meteorology (ANACM) for providing meteorological data. We are grateful to Aboubacar Said Anli, General Director of Health, for his interest in this work, and to those who collaborated at PNLP: Mohamed Hafidhou, Astafieva Marina, Amina Yssouf, Ali Toilibou, Hadidja Mohamed Soulé and Ahamadi Darouèche. We finally thank Christophe Révillion (University of La Réunion-UMR Espace-DEV) for his help and advice on remote sensing analysis.

Conflicts of Interest: The authors declare no conflict of interest.

\section{References}

1. World Health Organization. World Malaria Report 2017; WHO: Geneva, Switzerland, 2017; ISBN 978924 1565158 .

2. Ouledi, A. Épidémiologie et contrôle du paludisme en République Fédérale Islamique des Comores [The epidemiology and control of malaria in the Federal Islamic Republic of Comoros]. Cahiers d'études et de Recherches Francophones/Santé 1995, 5, 368-371. (In French)

3. Blanchy, S.; Benthein, F.; Sabatinelli, G. Epidémiologie du paludisme en République Fédérale Islamique des Comores: Données actuelles [Epidemiology of malaria in the Federal Islamic Republic of Comoros: Current data]. Cahiers ORSTOM Série Entomologie Médicale et Parasitologie 1987, 25, 45-52. (In French)

4. Toyb, M.; Ouledi, A.; Gaüzère, B.-A.; Aubry, P. Malaria in the Comoros Archipelago in 2015: Status after 15 years of fight. Bull. Soc. Pathol. Exot. 2016, 109, 107-113. [CrossRef] [PubMed]

5. Deng, C.; Huang, B.; Wang, Q.; Wu, W.; Zheng, S.; Zhang, H.; Li, D.; Feng, D.; Li, G.; Xue, L.; et al. Large-scale Artemisinin-Piperaquine Mass Drug Administration with or without Primaquine Dramatically Reduces Malaria in a Highly Endemic Region of Africa. Clin. Infect. Dis. 2018, 67, 1670-1676. [CrossRef]

6. Kassim, S.A.; James, P.B.; Alolga, R.N.; Assanhou, A.G.; Kassim, S.M.; Bacar, A.; Silai, R.; Tian, L.; Li, H.; Ma, A. Major decline in malaria morbidity and mortality in the Union of Comoros between 2010 and 2014: The effect of a combination of prevention and control measures. S. Afr. Med. J. 2016, 106, 709-714. [CrossRef]

7. Deng, C.; Wang, Q.; Zheng, S.; Zhou, C.; Gao, Y.; Guo, J.; Mliva, A.M.; Oithik, F.; Bacar, A.; Attoumane, R.; et al. Mass Drug Administration of Artemisinin-piperaquine on High Malaria Epidemic Area. Trop. Med. Health 2014, 42, 33-41. [CrossRef]

8. Blanchy, S.; Julvez, J.; Mouchet, J. Stratification épidémiologique du paludisme dans l'archipel des Comores [Epidemiological Stratification of Malaria in Comoro Archipelago, Indian Ocean]. Bull. Soc. Pathol. Exot. 1999, 92, 177-184. (In French)

9. Ouledi, A. Paludisme et Environnement aux Comores [Malaria and Environment in Comoros]. Ph.D. Thesis, Université Paris VI-Pierre et Marie Curie, Paris, France, 2003. (In French)

10. Papa Mze, N.; Ahouidi, A.D.; Diedhiou, C.K.; Silai, R.; Diallo, M.; Ndiaye, D.; Sembene, M.; Mboup, S. Distribution of Plasmodium species on the island of Grande Comore on the basis of DNA extracted from rapid diagnostic tests. Parasite 2016, 23, 34. [CrossRef]

11. Commisariat au Plan UDC. Enquête Démographique et de Santé et à Indicateurs Multiples [Demographic and Health Survey with Multiple Indicators] (EDSC-MICS II) 2012; Moroni, Comoros, 2014; (In French) Available online: https://microdata.worldbank.org/index.php/catalog/1999 (accessed on 10 December 2020).

12. Mohamed, I. L'eau en Grande Comore: étude de cas d'un petit espace insulaire abondamment arrosé mais en situation de pénurie d'eau [Water in Grande Comore: A case study of a small island area with abundant rainfall but water shortages.]. Ph.D. Thesis, Université de La Réunion, Saint-Denis, France, 2012. (In French)

13. Ohrt, C.; Roberts, K.W.; Sturrock, H.J.W.; Wegbreit, J.; Lee, B.Y.; Gosling, R.D. Information Systems to Support Surveillance for Malaria Elimination. Am. J. Trop. Med. Hyg. 2015, 93, 145-152. [CrossRef]

14. Yukich, J.O.; Butts, J.; Miles, M.; Berhane, Y.; Nahusenay, H.; Malone, J.L.; Dissanayake, G.; Reithinger, R.; Keating, J. A description of malaria sentinel surveillance: A case study in Oromia Regional State, Ethiopia. Malar. J. 2014, 13. [CrossRef] 
15. Mercado, C.E.; Ekapirat, N.; Dondorp, A.M.; Maude, R.J. An assessment of national surveillance systems for malaria elimination in the Asia Pacific. Malar. J. 2017, 16, 127. [CrossRef] [PubMed]

16. Randrianaivo, H.; Bertaut-Nativel, B.; André, M.; Irabe, M.; Robillard, P.-Y.; Boumahni, B.; Mangeas, M.; Roux, E.; Brou, T.Y.; Gérardin, P.; et al. Mise en place d'une surveillance spatialisée des malformations congénitales à La Réunion: Choix méthodologiques [Implementation of spatial surveillance of congenital malformations in Reunion Island (France): Methodological choices]. Bull. Epidémiol. Hebd. 2018, 2, $38-44$. (In French)

17. Robertson, C.; Nelson, T.A.; MacNab, Y.C.; Lawson, A.B. Review of methods for space-time disease surveillance. Spat. Spatio-Temporal Epidemiol. 2010, 1, 105-116. [CrossRef] [PubMed]

18. Kelly, G.C.; Hale, E.; Donald, W.; Batarii, W.; Bugoro, H.; Nausien, J.; Smale, J.; Palmer, K.; Bobogare, A.; Taleo, G.; et al. A high-resolution geospatial surveillance-response system for malaria elimination in Solomon Islands and Vanuatu. Malar. J. 2013, 12. [CrossRef]

19. Ma, S.; Lawpoolsri, S.; Soonthornworasiri, N.; Khamsiriwatchara, A.; Jandee, K.; Taweeseneepitch, K.; Pawarana, R.; Jaiklaew, S.; Kijsanayotin, B.; Kaewkungwal, J. Effectiveness of Implementation of Electronic Malaria Information System as the National Malaria Surveillance System in Thailand. JMIR Public Health Surveill. 2016, 2, e20. [CrossRef]

20. Rajatonirina, S.; Heraud, J.M.; Randrianasolo, L.; Orelle, A.; Razanajatovo, N.H.; Raoelina, Y.N.; Ravolomanana, L.; Rakotomanana, F.; Ramanjato, R.; Randrianarivo-Solofoniaina, A.E.; et al. Short message service sentinel surveillance of influenza-like illness in Madagascar, 2008-2012. Bull. World Health Organ. 2012, 90, 385-389. [CrossRef]

21. Girond, F.; Randrianasolo, L.; Randriamampionona, L.; Rakotomanana, F.; Randrianarivelojosia, M.; Ratsitorahina, M.; Brou, T.Y.; Herbreteau, V.; Mangeas, M.; Zigiumugabe, S.; et al. Analysing trends and forecasting malaria epidemics in Madagascar using a sentinel surveillance network: A web-based application. Malar. J. 2017, 16, 72. [CrossRef]

22. Eskenazi, B.; Quiros-Alcala, L.; Lipsit, J.M.; Wu, L.D.; Kruger, P.; Ntimbane, T.; Nawn, J.B.; Bornman, M.S.R.; Seto, E. mSpray: A mobile phone technology to improve malaria control efforts and monitor human exposure to malaria control pesticides in Limpopo, South Africa. Environ. Int. 2014, 68, 219-226. [CrossRef]

23. Herbreteau, V. When geography of health meets health ecology. In The Biogeography of Host-Parasite Interaction; Morand, S., Krasnov, B., Eds.; Oxford University Press: New York, NY, USA, 2010; pp. 247-265.

24. Stefani, A.; Dusfour, I.; Cruz, M.C.B.; Dessay, N.; Galardo, A.K.R.; Galardo, C.D.; Girod, R.; Gomes, M.S.M.; Gurgel, H.; Lima, A.C.F.; et al. Land cover, land use and malaria in the Amazon: A systematic literature review of studies using remotely sensed data. Malar. J. 2013, 12. [CrossRef]

25. Gebreslasie, M.T. A review of spatial technologies with applications for malaria transmission modelling and control in Africa. Geospat. Health 2015, 10, 328. [CrossRef]

26. Viana, J.; Santos, J.; Neiva, R.; Souza, J.; Duarte, L.; Teodoro, A.; Freitas, A. Remote Sensing in Human Health: A 10-Year Bibliometric Analysis. Remote Sens. 2017, 9, 1225. [CrossRef]

27. Odhiambo, J.N.; Kalinda, C.; Macharia, P.M.; Snow, R.W.; Sartorius, B. Spatial and spatio-temporal methods for mapping malaria risk: A systematic review. BMJ Glob. Health 2020, 5, e002919. [CrossRef] [PubMed]

28. Herbreteau, V.; Salem, G.; Souris, M.; Hugot, J.-P.; Gonzalez, J.-P. Thirty years of use and improvement of remote sensing, applied to epidemiology: From early promises to lasting frustration. Health Place 2007, 13, 400-403. [CrossRef] [PubMed]

29. Midekisa, A.; Senay, G.; Henebry, G.M.; Semuniguse, P.; Wimberly, M.C. Remote sensing-based time series models for malaria early warning in the highlands of Ethiopia. Malar. J. 2012, 11, 165. [CrossRef] [PubMed]

30. Fastring, D.R.; Griffith, J.A. Malaria incidence in Nairobi, Kenya and dekadal trends in NDVI and climatic variables. Geocarto Int. 2009, 24, 207-221. [CrossRef]

31. Krefis, A.C.; Schwarz, N.G.; Nkrumah, B.; Acquah, S.; Loag, W.; Oldeland, J.; Sarpong, N.; Adu-Sarkodie, Y.; Ranft, U.; May, J. Spatial analysis of land cover determinants of malaria incidence in the Ashanti Region, Ghana. PLoS ONE 2011, 6, e17905. [CrossRef]

32. Rakotoarison, H.A.; Rasamimalala, M.; Rakotondramanga, J.M.; Ramiranirina, B.; Franchard, T.; Kapesa, L.; Razafindrakoto, J.; Guis, H.; Tantely, L.M.; Girod, R.; et al. Remote Sensing and Multi-Criteria Evaluation for Malaria Risk Mapping to Support Indoor Residual Spraying Prioritization in the Central Highlands of Madagascar. Remote Sens. 2020, 12, 1585. [CrossRef] 
33. Li, Z.; Roux, E.; Dessay, N.; Girod, R.; Stefani, A.; Nacher, M.; Moiret, A.; Seyler, F. Mapping a Knowledge-Based Malaria Hazard Index Related to Landscape Using Remote Sensing: Application to the Cross-Border Area between French Guiana and Brazil. Remote Sens. 2016, 8, 319. [CrossRef]

34. Benz, U.C.; Hofmann, P.; Willhauck, G.; Lingenfelder, I.; Heynen, M. Multi-resolution, object-oriented fuzzy analysis of remote sensing data for GIS-ready information. ISPRS J. Photogramm. Remote Sens. 2004, 58, 239-258. [CrossRef]

35. Blaschke, T. Object based image analysis for remote sensing. ISPRS J. Photogramm. 2010, 65, 2-16. [CrossRef]

36. Kelly, M.; Blanchard, S.D.; Kersten, E.; Koy, K. Terrestrial Remotely Sensed Imagery in Support of Public Health: New Avenues of Research Using Object-Based Image Analysis. Remote Sens. 2011, 3, 2321. [CrossRef]

37. Foody, G.M. Status of land cover classification accuracy assessment. Remote Sens. Environ. 2002, 80, $185-201$. [CrossRef]

38. Russell, P.F.; Santiago, D. Flight Range of Anopheles in the Philippines. Am. J. Trop. Med. Hyg. 1934, s1-14, 407-424. [CrossRef]

39. Yeshiwondim, A.K.; Gopal, S.; Hailemariam, A.T.; Dengela, D.O.; Patel, H.P. Spatial analysis of malaria incidence at the village level in areas with unstable transmission in Ethiopia. Int. J. Health Geogr. 2009, 8, 5. [CrossRef]

40. Carter, R.; Mendis, K.N.; Roberts, D. Spatial targeting of interventions against malaria. Bull. World Health Organ. 2000, 78, 1401-1411.

41. McGarigal, K.; Cushman, S.; Ene, E. FRAGSTATS v4: Spatial Pattern Analysis Program for Categorical and Continuous Maps; Computer Software Program Produced by the Authors at the University of Massachusetts, Amherst; 2012. Available online: http://www.umass.edu/landeco/research/fragstats/fragstats.html (accessed on 10 December 2020).

42. QGIS Development Team. QGIS Geographic Information System; Open Source Geospatial Foundation Project: Chicago, IL, USA, 2020.

43. R Core Team. R: A Language and Environment for Statistical Computing; R Foundation for Statistical Computing: Vienna, Austria, 2020.

44. RStudio Team. RStudio: Integrated Development for R; RStudio, Inc.: Boston, MA, USA, 2020.

45. Moran, P.A.P. Notes on Continuous Stochastic Phenomena. Biometrika 1950, 37, 17-23. [CrossRef]

46. Getis, A.; Ord, J.K. The Analysis of Spatial Association by Use of Distance Statistics. Geogr. Anal. 1992, 24, 189-206. [CrossRef]

47. Anselin, L. Local Indicators of Spatial Association-LISA. Geogr. Anal. 1995, 27, 93-115. [CrossRef]

48. Kulldorff, M.; Mostashari, F.; Duczmal, L.; Katherine Yih, W.; Kleinman, K.; Platt, R. Multivariate scan statistics for disease surveillance. Stat. Med. 2007, 26, 1824-1833. [CrossRef]

49. Kulldorff, M. A spatial scan statistic. Commun. Stat. Theory Methods 1997, 26, 1481-1496. [CrossRef]

50. McCullagh, P.; Nelder, J.A. Generalized Linear Models; CRC Press: Boca Raton, FL, USA, 1989; Volume 37, ISBN 0-412-31760-5.

51. Fox, J.; Monette, G. Generalized collinearity diagnostics. J. Am. Stat. Assoc. 1992, 87, 178-183. [CrossRef]

52. Nguyen, M.; Howes, R.E.; Lucas, T.C.D.; Battle, K.E.; Cameron, E.; Gibson, H.S.; Rozier, J.; Keddie, S.; Collins, E.; Arambepola, R.; et al. Mapping malaria seasonality in Madagascar using health facility data. BMC Med. 2020, 18. [CrossRef] [PubMed]

53. Kazembe, L.N.; Kleinschmidt, I.; Holtz, T.H.; Sharp, B.L. Spatial analysis and mapping of malaria risk in Malawi using point-referenced prevalence of infection data. Int. J. Health Geogr. 2006, 5, 41. [CrossRef] [PubMed]

54. Maxwell, C.A.; Chambo, W.; Mwaimu, M.; Magogo, F.; Carneiro, I.A.; Curtis, C.F. Variation of malaria transmission and morbidity with altitude in Tanzania and with introduction of alphacypermethrin treated nets. Malar. J. 2003, 2, 28. [CrossRef]

55. Tantely, M.L.; Rakotoniaina, J.C.; Tata, E.; Andrianaivolambo, L.; Fontenille, D.; Elissa, N. Modification of Anopheles gambiae distribution at high altitudes in Madagascar. J. Vector Ecol. J. Soc. Vector Ecol. 2012, 37, 402-406. [CrossRef] [PubMed]

56. Parselia, E.; Kontoes, C.; Tsouni, A.; Hadjichristodoulou, C.; Kioutsioukis, I.; Magiorkinis, G.; Stilianakis, N.I. Satellite Earth Observation Data in Epidemiological Modeling of Malaria, Dengue and West Nile Virus: A Scoping Review. Remote Sens. 2019, 11, 1862. [CrossRef] 
57. Ihantamalala, F.A.; Herbreteau, V.; Rakotoarimanana, F.M.J.; Rakotondramanga, J.M.; Cauchemez, S.; Rahoilijaona, B.; Pennober, G.; Buckee, C.O.; Rogier, C.; Metcalf, C.J.E.; et al. Estimating sources and sinks of malaria parasites in Madagascar. Nat. Commun. 2018, 9, 3897. [CrossRef]

58. Baragatti, M.; Fournet, F.; Henry, M.C.; Assi, S.; Ouedraogo, H.; Rogier, C.; Salem, G. Social and environmental malaria risk factors in urban areas of Ouagadougou, Burkina Faso. Malar. J. 2009, 8, 13. [CrossRef]

59. Kreuels, B.; Kobbe, R.; Adjei, S.; Kreuzberg, C.; von Reden, C.; Bater, K.; Klug, S.; Busch, W.; Adjei, O.; May, J. Spatial variation of malaria incidence in young children from a geographically homogeneous area with high endemicity. J. Infect. Dis. 2008, 197, 85-93. [CrossRef]

Publisher's Note: MDPI stays neutral with regard to jurisdictional claims in published maps and institutional affiliations.

(C) 2020 by the authors. Licensee MDPI, Basel, Switzerland. This article is an open access article distributed under the terms and conditions of the Creative Commons Attribution (CC BY) license (http://creativecommons.org/licenses/by/4.0/). 